\title{
ПОВЫШЕНИЕ ЭНЕРГОЭФФЕКТИВНОСТИ КАК ДРАЙВЕР РОСТА ВВП РОССИИ
}

\section{INCREASING ENERGY EFFICIENCY AS A DRIVER OF GDP GROWTH IN RUSSIA}

A. Khokhlov

S. Vasin

Summary. To increase GDP growth, it becomes increasingly important not only to increase production volumes and enter new markets, but also to reduce current unit costs of production. Reducing energy intensity of production is one of the significant cost items, given the high share of energy-intensive production of Russia in the structure of GDP solution of this problem is an urgent challenge of our time. In the course of this work, the degree of impact of energy intensity on the country's GDP was analyzed, and a set of measures aimed at improving energy efficiency was proposed.

Keywords: energy efficiency, GDP, energy intensity of GDP, economic growth, economic development.

\author{
Хохлов Антон Васильевич \\ Российский экономический университет имени \\ Г.В. Плеханова \\ anton.khokhlov2013@yandex.ru \\ Васин Сергей Григорьевич \\ К.э.н., дочент, Российский экономический \\ университет имени Г.В. Плеханова \\ vasin.sg@rea.ru
}

Аннотация. Для увеличения роста ВВП все большее значение приобретает не только наращивание объемов производства и выход на новые рынки, но и сокращение текущих удельных затрат. Снижение энергоемкости производства является одной из существенных статей затрат, учитывая высокую долю энергоемкого производства России В структуре ВВП решение данной задачи является актуальным вызовом современности. В ходе проведенной работы проанализирована степень влияния энергоемкости на ВВП страны, а также предложен комплекс мероприятий, направленный на повышение энергоэффективности.

Ключевые слова: энергоэффективность, ВВП, энергоемкость ВВП, экономический рост, экономическое развитие.
$\mathbf{P}$ оссия занимает 3-е место в мире по объему производства энергии (после Китая и США), при этом Россия является страной с высоким удельным энергопотреблением на единицу произведенной продукции (энергопотребление России в среднем в 2 раза превышает среднемировое значение). Таким образом, проблематика вопроса повышения энергоэффективности является очень важным вопросом, поскольку, наращивая производственные мощности исключительно только за счет факторов экстенсивного экономического роста и не внедряя технологические и правовые механизмы снижения энергопотребления является неэффективной и убыточной в долгосрочной перспективе стратегией.

Целью написания данной статьи является установление причинно-следственных связей между темпами роста ВВП страны и уровнем энергоемкости ее продукции, поскольку повышение уровня энергоээфективности потенциально открывает дополнительные возможности роста ВВП за счет снижения уровня удельных затрат продукции и повышения научного потенциала страны. В ходе написания статьи основной упор был сделан на анализ имеющихся статистических данных ВВП и энергоемкости для установления степени корреляции между исследуемыми величинами и последующего системного анализа проводимых мероприятий по повышению энергоемкости.

Понятие энергоэффективности и энергоемкости неразрывно связано с популярной метрикой «экономического успеха» - ВВП. Валовый внутренний продукт (далее ВВП) является одним из наиболее известных макроэкономических показателей, отражающим уровень благосостояния общества, поскольку позволяет оценить уровень эффективности экономической деятельности и социального прогресса страны в стоимостном выражении. ВВП - показатель, выражающий в денежном эквиваленте рыночную стоимость всех товаров и услуг, произведенных на территории определенного государства, вне зависимости от национальной принадлежности используемых факторов производства.

В свою очередь измерение уровня ВВП неразрывно связано с уровнем энергоемкости ВВП, и, обратным ему показателем - уровнем энергоэффективности ВВП. К.Д. Савичев и В.В. Глухов под энергоемкостью ВВП понимают показатель, характеризующий затраты энергетического ресурса, необходимого на производство единицы полезного эффекта продукции (товаров, работ 


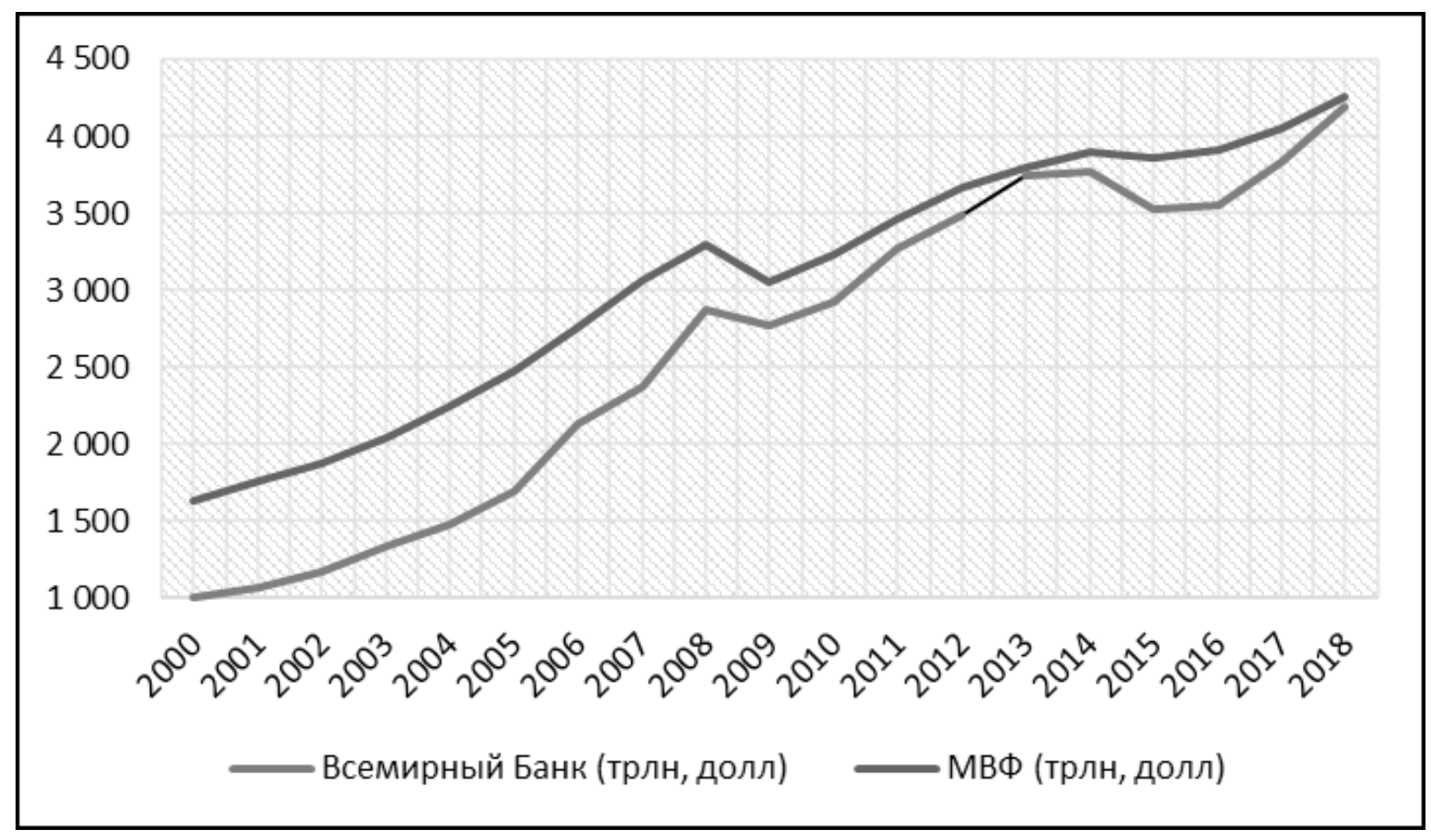

Рис. 1. Динамика ВВП России по ППС, 2000-2018 гг.

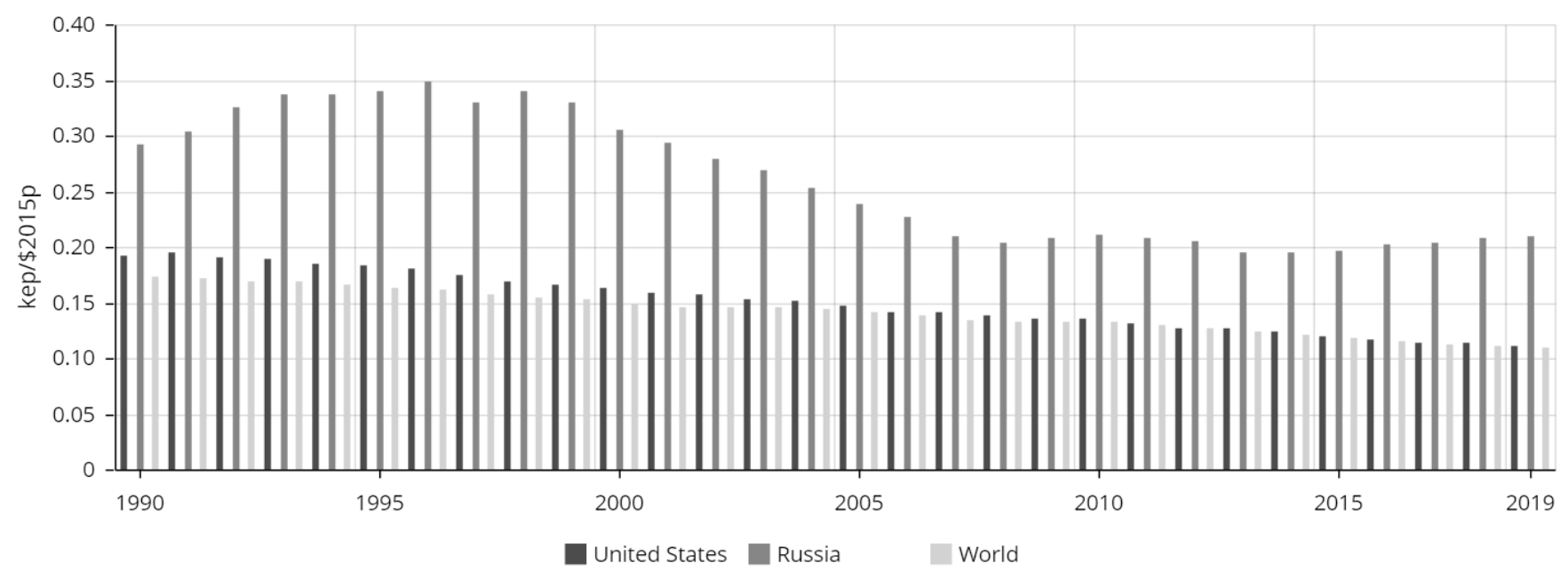

Рис. 2. Бенчмаркинг России США и мира по уровню энергоемкости, 1990-2019 гг.

и услуг). [2] И действительно, любая сфера экономической деятельности, направленной на вклад в создание ВВП страны неразрывно связана с потреблением энергии (электрической, тепловой и т.д.) в любом секторе производства, будь то горнодобывающее производство или же IT-компания.

На рис. 1 представлен график изменения уровня ВВП России за период с 2000 по 2018 гг. по паритету покупательной способности (далее ППС) к функциональной валюте Доллар США на основе данных Всемирного банка и Международного валютного фонда. [6,7]
Измерение ВВП по ППС является наиболее объективным отражением уровня ВВП, поскольку отражает уровень ВВП, являющийся паритетным к покупательной способности определенного набора товаров и услуг в валютах разных стран.

Исходя из данного графика можно отметить что уровень ВВП по ППС за период с 2009 по 2018 гг. увеличивался в среднем на 4\%, при этом уровень ВВП в 2018 г. по отношению к 2009 г. на основе среднего значения Всемирного Банка и МВФ увеличился на $45 \%$ и составил 4,226 трлн. долл. против 2,914 трлн. долл. в 2009 г. 
Временной отрезок с 2009 по 2018 гг. рассматривается в рамках данной статьи поскольку именного в 2009 г. был принят Федеральный закон «Об энергосбережении и о повышении энергетической эффективности» от 23.11.2009 № 261-Ф3. [1] Данный законопроект предусматривает своей целью создание различных стимулирующих основ (правовых, экономических и т.д.) направленных на повышение энергетической эффективности и как следствие повышение экономического роста России за счет снижения энергоемкости, приходящейся на единицу ВВП.

В первой редакции данный законопроект предусматривал глобальной целью снижение энергоемкости ВВП России на 40\% к 2020 г. Однако с 2015 г. программа поддержки проектов энергоэффективности была свернута, а по результатам прошедших десяти лет Министерство экономического развития констатировало снижение энергоемкости лишь на 9\% от планового уровня и в течении 2020 г. разрабатывало новую версию плана по снижению энергоемкости. [3] Таким образом за период 2009-2019 гг. Россия наращивала объем ВВП исключительно за счет повышения уровня производства, не используя технологические и правовые факторы для снижения энергоемкости ВВП - темп снижения энергоемкости в среднем составлял $0.4 \%$ и практически не изменился от уровня 2010 года. [9]

На рисунке 2 приводятся сравнительные показатели затрат на единицу ВВП по среднегодовому курсу доллара США в 2015 г., поскольку после 2015 г. рынок энергоресурсов стал более волатильным, особенно это отразилось на снижении стоимости нефти в 2015 г. Как видно из данного графика средняя энергоемкость США несколько превышает общемировой уровень, но в целом находится в тренде, в то время как энергоемкость России существенно выше.

В августе 2020 г. Минэкономики направило в Правительство РФ обновленную версию плана повышения энергоэффективности России, предусматривающую снижение уровня энергоемкости ВВП к 2030 г. на 35\% от уровня 2017 г., что составит около $42 \%$ от уровня 2009 г. Помимо снижения энергоемкости, данная программа также предусматривает повышение уровня эффективности бизнес-процессов в сфере производства, потребления и логистики ресурсов. Также одним из новшеств является синхронизация данной программы со стратегией низкоуглеродного развития. Стратегия низкоуглеродного развития ставит своей целью снижение уровня выбросов парниковых газов на территории России к 2030 г. на треть от уровня 1990 г. и как следствие снижение уровня углеродоемкости российского ВВП на 9\%. $[4,10]$
В опубликованном государственном докладе «O состоянии энергосбережения и повышении энергетической эффективности в Российской Федерации» за период 2019 г., приводится ряд, успешных кейсов компаний и субъектов РФ в сфере повышения уровня энергоэффективности и энергосбережения, а также описаны планируемые показатели экономии энергоресурсов и методы, способные достичь этого. Так, в сфере электроэнергетики авторы доклада выделяют правовые инициативы в сфере закрепления экологических стандартов для дизельных электростанций и введение минимальных пороговых значений КПД для объектов генерации как ключевые драйверы, способные повысить энергоэффективность в данной сфере. [7,8]

Можно отметить что профильные министерства и ведомства осознают актуальность и уровень проблемы по снижению энергоемкости ВВП России и предпринимают необходимые правовые и технологические решения по повышению данного показателя. Для снижения доли энергоемкости ВВП положительный эффект, помимо обозначенных мероприятий в Плане повышения энергоэффективности России, способны оказать следующие инициативы:

- стимулирование перехода на более совершенное технологическое оборудование, путем создания налоговых льгот и понижающих коэффициентов для компаний, осуществляющих замену устаревшего оборудования;

- оказание мер государственной поддержки (научные гранты, субсидии и т.д.) исследовательским институтам, занимающимся исследованием проблем повышения энергоэффективности и разработкой перспективных технологий в данной сфере;

- расширить статью 150 НК РФ положением о льготной ставке таможенных пошлин при ввозе комплектующих к промышленному оборудованию объектов генерации, обладающим наилучшими показателями экологического воздействия на окружающую среду и высокой степенью энергоэффективности.

Также хорошим примером может служить опыт Евросоюза и США, касательно изменения структуры энергобаланса в сторону повышения доли возобновляемых источников энергии, так, в результате активного продвижения данной инициативы с 2000 года им удалось уровень энергопотребления более чем на $30 \%$ исключительно за счет изменения структуры энергобаланса в сторону повышения ВИЭ, ужесточения требований в рамках экологического законодательства и повышения технических стандартов к электрическому оборудованию в части снижения его энергозатрат. Однако, необходимо помнить, что существенную роль 
также играет и структура ВВП стран, так наибольшую капитализацию в США показывают компании IT и ТМT секторов, в России же доля технологических компаний пока не столь велика, а основой формирования ВВП является энергоемкая производственная деятельности, поэтому результат от внедрения данных мер может показать более низкий процент снижения энергоемкости, однако в любом случае это окажет положительный эффект.

В рамках данной статьи на основе проведенного анализа мирового уровня энергопотребления и энергоемкости мира и стран в частности, удалось выявить лидеров в данном направлении, а также оценить текущую позицию России, а также провести интерпретацию темпов роста ВВП России к уровню энергоемкости. Результатом анализа стало обнаружение высокой энергоемкости продукции, производимой на территории России, находящееся на стабильно высоком уровне на протяжении 2005-2019 гг., что свидетельствует о высокой степени практической значимости активного формирования и внедрения правовых и экономических инициатив, направленных на решение данного вопроса.
В ходе аналитического обзора информации по данной проблематики, освещение проблем повышения энергоэффективности России ранее не рассматривалось применительно к динамике темпов роста ВВП, что опосредует научную новизну работы, поскольку при наложении графиков темпа роста ВВП к графику энергоемкости, можно отметить отсутствие корреляции между величиной энергоэффективности и динамикой роста ВВП страны, что потенциально занижало темпы роста ВВП. Именно поэтому работы в данном направлении способны стать существенным драйвером роста благосостояния страны в будущем.

Таким образом обновление проекта Плана повышения энергоэффективности и Стратегии снижения уровня парниковых газов свидетельствует о внимании к данной проблеме со стороны органов исполнительной власти в лице Министерства экономического развития и Министерства энергетики, поэтому, предлагаемые авторами статьи мероприятия по повышению энергетического потенциала страны способны оказать практическую ценность при внедрении и дальнейшем формировании инициатив для выполнения поставленных в данных документах задач.

\section{ЛИТЕРАТУРА}

1. 06 энергосбережении и о повышении энергетической эффективности и о внесении изменений в отдельные законодательные акты Российской Федерации: Федеральный закон от 23.11.2009 № 261-Ф3 // Собрание законодательства РФ. — 2009.— № 48.— Ст. 5711.

2. Савичев К.Д., Глухов В.В. Влияние энергоемкости ВВП на качество жизни: показатели оценки и методы государственной поддержки // Научно-технические ведомости Санкт-Петербургского государственного политехнического университета. Экономические науки. — 2018.— T. 11.— № . 1.

3. Давыдова, А. Энергоэффективности обновили приоритеты / А. Давыдова // Коммерсантъ.— 2021.—№ 6/П.— С. 2.

4. Давыдова, А. Энергоэффективности обновили цель и средства / А. Давыдова // Коммерсантъ.— 2020.— № 142.— C. 2.

5. Сайт Всемирного Банка [Электронный ресурс] — Режим доступа: https://www.worldbank.org/en/home (дата обращения: 01.02.2021).

6. Сайт Международного валютного фонда [Электронный ресурс] — Режим доступа: https://www.imf.org/en/Home (дата 0бращения: 01.02.2021).

7. Сайт Министерства экономического развития Российской Федерации [Электронный ресурс] — Режим доступа: https://www.economy.gov.ru/ (дата обращения: 05.02.2021).

8. Сайт Министерства энергетики Российской Федерации [Электронный ресурс] — Режим доступа: https://minenergo.gov.ru/ (дата 0бращения: 02.02.2021).

9. Статистический Ежегодник мировой энергетики [Электронный ресурс] — Режим доступа: https://yearbook.enerdata.ru/ (дата обращения: 27.01.2021).

10. России прописали низкоуглеродное будущее [Электронный ресурс] — Режим доступа: https://www.kommersant.ru/doc/4299377 (дата обращения: 29.01.2021).

( ) Хохлов Антон Васильевич ( anton.khokhlov2013@yandex.ru ), Васин Сергей Григорьевич ( vasin.sg@rea.ru ). Журнал «Современная наука: актуальные проблемы теории и практики» 